\title{
Cobertura vacinal do esquema básico para o primeiro ano de vida nas capitais do Nordeste brasileiro
}

\author{
Coverage of the basic immunization schedule \\ in the first year of life in State capitals in \\ Northeast Brazil
}

\author{
Cobertura de vacunación de esquema básico \\ durante el primer año de vida en las capitales \\ del nordeste brasileño
}

\author{
Lorena Lauren Chaves Queiroz ${ }^{1}$ \\ Silvio Gomes Monteiro 1 \\ Elba Gomide Mochel 1 \\ Maria Amélia de Sousa Mascena Veras 2 \\ Francisca Georgina Macêdo de Sousa 3 \\ Márcio Lee de Meneses Bezerra 4 \\ Maria Bethânia da Costa Chein 1 \\ Grupo Inquérito Cobertura Vacinal 20075
}

\footnotetext{
1 Programa de Pós-graduação em Saúde Materno-Infantil, Universidade Federal do Maranhão, São Luís, Brasil. 2 Faculdade de Ciências Médicas, Santa Casa de São Paulo, São Paulo, Brasil. 3 Departamento de Enfermagem, Universidade Federal do Maranhão, São Luís, Brasil.

4 Departamento de Medicina Universidade Federal do Maranhão, São Luís, Brasil. 5 Outros membros listados ao final do artigo.

Correspondência L. L. C. Queiroz Programa de Pós-graduação em Saúde Materno-Infantil, Universidade Federal do Maranhão.

Rua 92 A, quadra 73, casa 04, São Luís, MA

65074-350, Brasil.

lorenalcq@yahoo.com.br
}

\section{Abstract}

Vaccination coverage in the so-called "developing countries" is still lower than expected. Such coverage is an important indicator of population health and the quality of care provided by the health care system. The current study describes the results of a household survey to estimate coverage of the basic immunization schedule in the first year of life in State capitals in Northeast Brazil, for the 2005 birth cohort. The methodology used was that recommended by the Pan American Health Organization for surveys on vaccination coverage. According to the data, vaccination coverage fell short of the goals set by the National Immunization Program for this age group, at high risk of acquiring vaccine-preventable diseases. The lowest coverage rates were found at the two extremes of socioeconomic strata. Assessment of vaccination coverage indicates whether the infant population is immunized and helps identify weak points in vaccination activities.

Immunization Coverage; Immunization; Infant; Surveys

\section{Resumo}

A cobertura vacinal nos chamados "países em desenvolvimento" ainda está aquém da esperada. Ela é um importante indicador de saúde das populações e da qualidade da atenção dispensada pelos serviços. O presente estudo descreve os resultados de um inquérito domiciliar para estimar a cobertura vacinal do esquema básico para o primeiro ano de vida nas capitais do Nordeste brasileiro, da coorte nascida em 2005. A metodologia usada é a preconizada pela Organização Pan-Americana da Saúde para a realização de inquéritos de cobertura vacinal. Os dados obtidos no presente estudo de cobertura vacinal demonstram que é baixa a proporção de crianças vacinadas, ao se considerarem as metas preconizadas pelo Programa Nacional de Imunização, na faixa etária de maior risco para as doenças imunizáveis. Para os estratos nas capitais do Nordeste, encontramos as piores coberturas nos dois extremos dos estratos socioeconômicos. A avaliação da cobertura vacinal contribui para detectar se a população infantil encontra-se imunizada, além da identificação de pontos frágeis das atividades de vacinação.

Cobertura Vacinal; Imunização; Lactente; Inquéritos 


\section{Introdução}

É inquestionável a importância que as vacinas têm na proteção à saúde e na prevenção de doenças imunopreveníveis, particularmente durante a infância. Em função disso, as autoridades de saúde, em todo o mundo, estabeleceram programas de imunizações e calendários específicos de vacinas de acordo com a faixa etária infantil. No Brasil, o Ministério da Saúde estabeleceu um amplo programa de imunizações de rotina e promove, periodicamente, campanhas com o intuito de controlar e erradicar doenças mediante vacinação maciça de crianças 1 .

Ainda assim, muitas crianças deixam de ser vacinadas pelos mais diferentes fatores, que abrangem desde o acesso aos serviços de saúde, até causas relacionadas a crenças, superstições, mitos e credos religiosos 2 .

A cobertura vacinal - definida como o percentual de uma população-alvo que foi vacinada - nos chamados "países em desenvolvimento" ainda se encontra aquém da esperada 3 . Ela é um importante indicador de saúde das populações, sobretudo das crianças e da qualidade da atenção dispensada pelos sistemas e serviços de saúde. O estudo desse indicador subsidia o processo de planejamento, especialmente a reestruturação das ações de prevenção e proteção à saúde 4

No Brasil, a cobertura vacinal tem sido estimada no país pelos registros das unidades de saúde, estando sujeita a importantes erros de registro de dados, transcrição, estimativa de população-alvo, dentre outros. A ocorrência de epidemias na vigência de estimativas de coberturas altas tem demonstrado a imprecisão de tais estimativas 5 . Além disso, as estimativas baseadas em dados administrativos apresentam limitações, especialmente em grandes núcleos populacionais, pois podem ocultar grandes diferenciais intraurbanos 6 .

O monitoramento da cobertura vacinal é um instrumento indispensável à avaliação dos programas de imunização. Para superar as limitações, o Programa Nacional de Imunizações (PNI) tem promovido inquéritos populacionais que objetivam melhor estimar a cobertura vacinal no país 7 .

Vários estudos de avaliação da cobertura vacinal e dos fatores relacionados à não vacinação realizados em amostras representativas da população infantil foram desenvolvidos no mundo e no Brasil para elucidar essa questão 5,7,8,9,10.

Entende-se que a efetividade de um programa de imunização, mensurada por intermédio da cobertura vacinal de uma população, está condicionada pelo sistema de saúde, pelo pró- prio programa de imunização e pelas características da população ${ }^{11}$.

Considerando que o estudo das coberturas vacinais, segundo condições de vida, fornece uma oportunidade para a investigação acerca da concretização de políticas públicas compensatórias, o presente estudo tem como objetivo descrever a cobertura vacinal do esquema básico para o primeiro ano de vida nas capitais do Nordeste brasileiro, comparando a taxa em diferentes estratos socioeconômicos.

\section{Métodos}

Os dados utilizados no estudo são provenientes do inquérito de cobertura vacinal nas áreas urbanas das capitais brasileiras - uma pesquisa multicêntrica - ocorrido no ano de 2007/2008, abrangendo as 26 capitais brasileiras mais o Distrito Federal, realizado pelo Centro de Estudos Augusto Leolpoldo Ayrosa Galvão (CEALAG) do Departamento de Medicina Social, Faculdade de Ciências Médicas da Santa Casa de São Paulo (FCMSCSP), em parceria com diversas universidades, com apoio de diversas secretarias estaduais e municipais de saúde.

Adotou-se como pressuposto para o cálculo do tamanho da amostra uma cobertura esperada de $80 \%$, nível de significância de 0,05 , precisão da estimativa de 0,07 , efeito do desenho de 1,5 e estimativa de perdas de 0,10. Com base nesses valores, estimou-se um número mínimo de 210 crianças por inquérito em trinta conglomerados de sete crianças. Utilizou-se como referência a amostragem por conglomerado proposta pela Organização Mundial da Saúde (OMS), para a realização de inquéritos de cobertura vacinal 2 . Dependendo do tamanho populacional, foram feitos de dois a cinco inquéritos em cada capital.

O estudo foi elaborado com delineamento de coorte retrospectiva transversal e amostragem probabilística estratificada em três estágios. $\mathrm{Pa}-$ ra a construção dos estratos socioeconômicos, efetuou-se uma classificação dos setores censitários por meio dos mapas dos setores censitários do Instituto Brasileiro de Geografia e Estatística (IBGE. Censo demográfico de 2000. http://www. ibge.gov.br) e das respectivas populações para cada uma das capitais, procedendo-se à ordenação decrescente dos setores censitários baseada na renda média do chefe de família, na porcentagem de domicílios cujos chefes recebem mais de vinte salários mínimos ( $\mathrm{R} \$ 545,00$ ) e na porcentagem de domicílios cujos chefes têm mais de 17 anos de estudo, de acordo com os dados dos setores censitários do IBGE. Às variáveis foi atribuído o mesmo peso. A soma dos três escores 
foi usada para criar quintis (denominados A, B, C, D e E) em cada capital, de forma que a combinação de maiores salários e anos de estudo estão no quintil de melhor situação socioeconômica (estrato A) e aqueles com a pior combinação de salário e anos de estudo ficaram no quintil com pior situação socioeconômica (estrato E).

Considerando-se o decréscimo na taxa de natalidade ocorrido no país desde o Censo Demográfico de 2000, os setores censitários foram agrupados de maneira que cada conglomerado tivesse ao menos 56 crianças na faixa etária de zero a quatro anos.

As informações foram obtidas por questionário estruturado e aplicado em entrevistas domiciliares, realizadas por entrevistadores treinados e supervisionados. Com o questionário, foram coletadas informações concernentes à vacinação das crianças. Nos domicílios em que havia mais de uma criança na faixa etária preconizada, a criança que fazia aniversário na data mais próxima da entrevista era a escolhida. A fonte de informação utilizada foi a caderneta de vacinação da criança, da qual se copiavam os dados referentes às doses e datas de aplicação das vacinas.

As entrevistas foram digitadas em banco de dados; o processamento e a análise dos dados foram feitos com o Epi Info, versão 3.4.3 (Centers for Disease Control and Prevention, Atlanta, Estados Unidos). A porcentagem de doses aplicadas e os intervalos de confiança foram calculados tendo em vista o efeito do desenho.

Foram definidas como esquema vacinal completo as doses de cada uma das vacinas com aplicação prevista para o primeiro ano de vida (três doses de vacina oral contra a poliomielite, contra a hepatite B e tetravalente - difteria, tétano, coqueluche e Haemophilus influenzae tipo B), acrescentada à tríplice viral. Para a faixa etária em pauta, preconiza-se apenas uma dose da tríplice viral.

O protocolo da pesquisa foi aprovado pelo Comitê de Ética em Pesquisa da Santa Casa de São Paulo, sendo também submetido e aprovado pelo Comitê de Ética em Pesquisa do Hospital Universitário/UFMA, sob parecer de no 33104$1729 / 2007$. Durante a pesquisa, foram observados aspectos contidos na Resolução no 196/96 do Conselho Nacional de Saúde, que trata de pesquisas com seres humanos. Foi assinado o Termo de Consentimento Livre e Esclarecido (TCLE) pelo responsável pela criança, no qual constavam a possibilidade de não participar da pesquisa, os benefícios que os resultados poderiam trazer à população, além de se procurar garantir a privacidade durante a aplicação do questionário.

\section{Resultados}

As coberturas obtidas para a vacina BCG foram as maiores em todas as capitais, talvez porque praticamente não exista restrição para considerar uma dose aplicada como válida. Estas, no momento do estudo, estiveram todas acima de $85 \%$. As capitais que tiveram maiores taxas de vacinação foram Maceió (Alagoas), Fortaleza (Ceará) e Teresina (Piauí), porém se observam diferenças de cobertura entre os estratos em todas as capitais. Teresina e Maceió obtiveram 100\% de cobertura para BCG no estrato E (Figura 1).

Em relação à vacina contra hepatite $\mathrm{B}$, Teresina destaca-se pela obtenção da maior cobertura $(84 \%)$ em todos os estratos. As outras capitais mantêm entre si um percentual homogêneo. São Luís (Maranhão) é uma das capitais que apresenta os menores percentuais em todos os estratos, não conseguindo atingir $80 \%$ em nenhum deles (Figura 2).

Para a vacina DPT, as coberturas no momento do estudo estiveram acima de $80 \%$ em todas as capitais, com variações significativas entre os estratos. Em Recife (Pernambuco), o estrato A obteve a menor cobertura (83\%). As melhores coberturas pertencem à Teresina, cujo percentual obtido foi acima de 95\% nos estratos B, C, D e E, sendo menor no estrato A; já em Salvador (Bahia), o estrato A é o de melhor desempenho (96,5\%), assim como os estratos D e E de Natal (Rio Grande do Norte), com 97\%. As menores taxas de cobertura são observadas em São Luís, só apresentando coberturas superiores a $85 \%$ no estrato A (Figura 3).

Para a vacina Hib, verificam-se coberturas acima de $77 \%$ na maioria das capitais, especialmente em Teresina, Fortaleza, Aracaju (Sergipe), Natal e Maceió, sem diferenças significativas entre os estratos. Recife apresentou as menores coberturas, particularmente nos estratos A (56\%), C e D (65\%) e E (64\%). A cobertura com a referida vacina é ligeiramente menor do que a com a vacina DPT, sobretudo em Recife onde somente $2 / 3$ das crianças receberam as três doses da vacina. Uma hipótese para explicar essa baixa cobertura é o registro da vacina tetravalente na coluna da vacina DPT na caderneta de vacinação, pois à época já estava disponível a vacina tetravalente (Figura 4).

As coberturas para a vacina tríplice viral atingiram valores superiores a $80 \%$ em todos os estratos de Teresina, Fortaleza, Aracaju e Natal. São Luís apresentou coberturas abaixo de $80 \%$ em todos os estratos (Figura 5). Chama a atenção o fato de que a cobertura alcançada nos diferentes estratos das capitais foi praticamente homogênea, sem diferenças significativas entre eles. 
Cobertura vacinal para BCG, no primeiro ano de vida, segundo capitais do Nordeste brasileiro e estrato social, na coorte de nascimento de 2005.

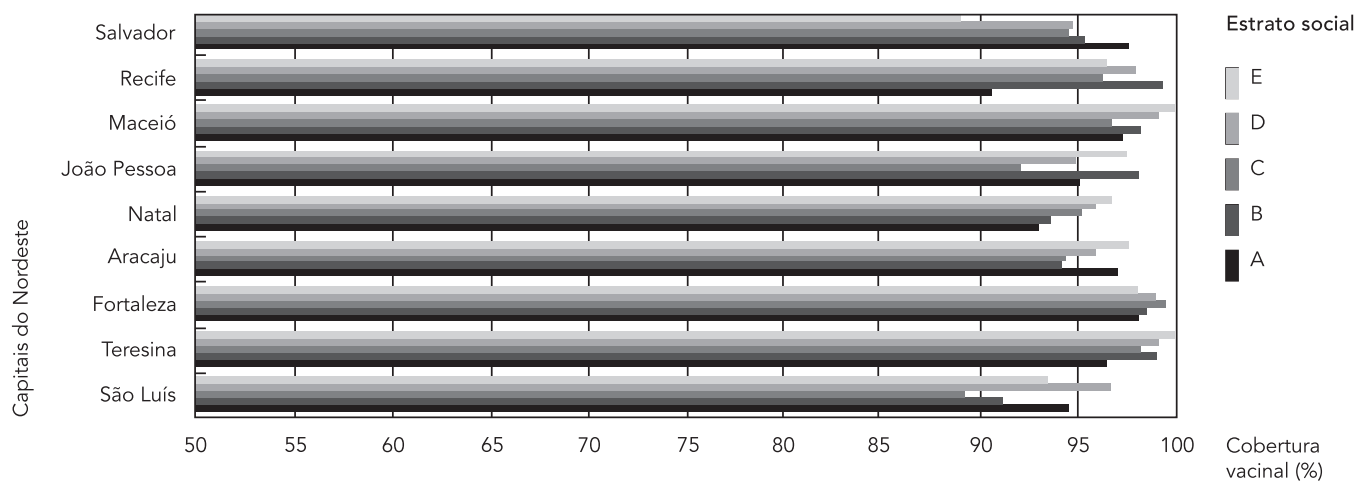

Figura 2

Cobertura vacinal para hepatite B, no primeiro ano de vida, segundo capitais do Nordeste brasileiro e estrato social, na coorte de nascimento de 2005.

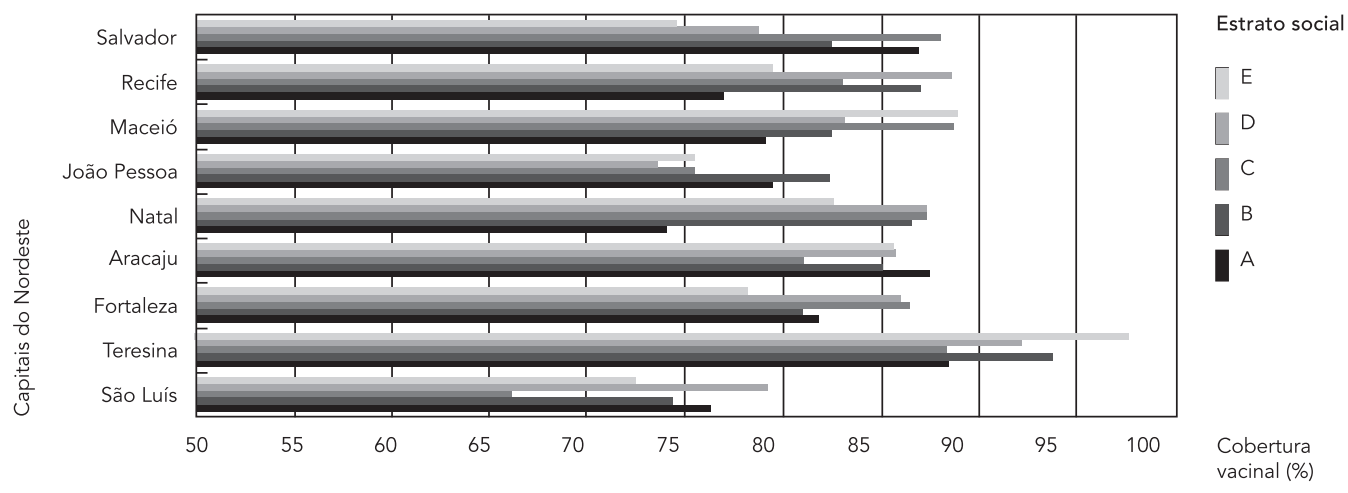

Foram obtidos dados referentes às coberturas da vacina antipólio (oral) que se mostraram altas na maioria das capitais e dos estratos em todas as áreas consideradas, com valores superiores a 85\%, com exceção do estrato A de Recife, e sem diferenças significativas entre elas. Pela frequência com que são feitas as campanhas nacionais de imunização contra a poliomielite, oferecendo múltiplas oportunidades para a vacinação das crianças menores de cinco anos, esperava-se maiores percentuais para todas as capitais nos diferentes estratos (dados não apresentados).
$\mathrm{Na}$ maioria das capitais o estrato E foi o que apresentou maiores percentuais de cobertura para a vacina antipólio (oral), próximos a $90 \%$, com exceção de Salvador que atingiu apenas $85 \%$ de cobertura. As melhores coberturas pertencem à Teresina onde todos os estratos estão acima de 95\% de cobertura; Recife e Fortaleza apresentam as piores coberturas no estrato A. De uma forma geral, São Luís foi a capital que apresentou as menores coberturas em praticamente todos os estratos. Tais valores podem indicar que as camadas mais pobres da população têm acesso à 
Cobertura vacinal para DPT, no primeiro ano de vida, segundo capitais do Nordeste brasileiro e estrato social, na coorte de nascimento de 2005.

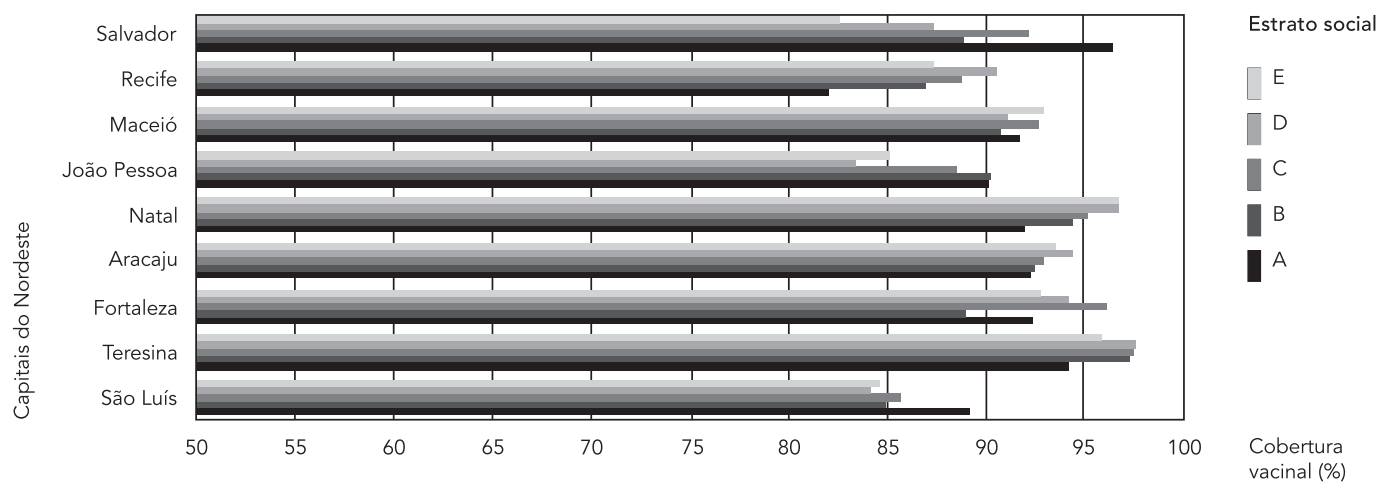

Figura 4

Cobertura vacinal para Hib, no primeiro ano de vida, segundo capitais do Nordeste brasileiro e estrato social, na coorte de nascimento de 2005.

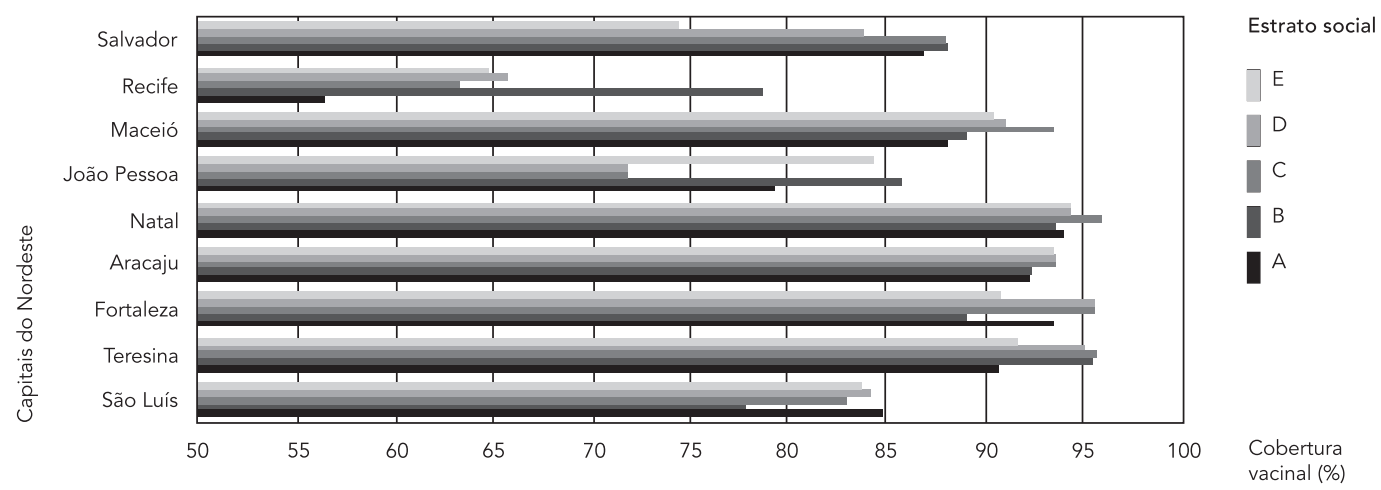

vacinação preferencialmente durante as campanhas, tendo maiores dificuldades em consumir os serviços regulares de saúde.

A vacina contra febre amarela não está incluída como vacina obrigatória no calendário básico das crianças em todas as capitais. As capitais do Nordeste que possuem essa vacina incluída nas ações de rotina são os estados do Maranhão, alguns municípios dos estados do Piauí e da Bahia, o que justifica a inexistência e as baixas coberturas em algumas capitais como Recife, João Pes- soa (Paraíba), Natal, Aracaju e Fortaleza. Teresina possui cobertura superior a $85 \%$ em todos os estratos. Salvador atinge valores acima de $80 \%$ nos estratos intermediários B, C e D e São Luís apenas no estrato A e D. Esses dados não foram apresentados uma vez que a vacina contra febre amarela não está incluída como vacina obrigatória no calendário básico e a proposta do estudo é apresentar os resultados do esquema básico. 
Cobertura vacinal para SCR, no primeiro ano de vida, segundo capitais do Nordeste brasileiro e estrato social, na coorte de nascimento de 2005.

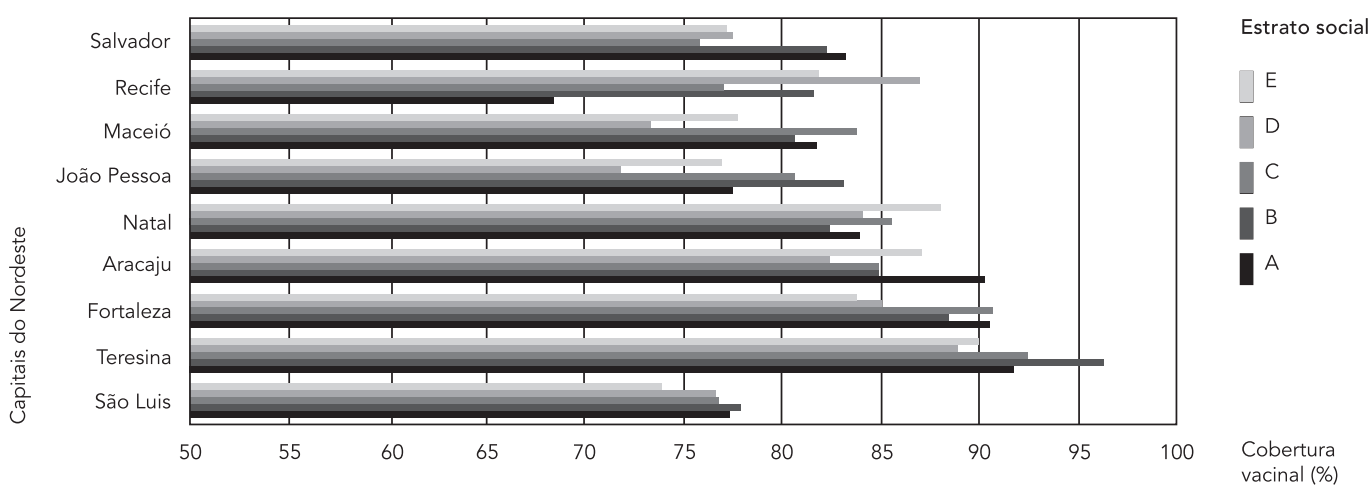

\section{Discussão}

$\mathrm{Na}$ análise de cada vacina de forma isolada, as coberturas observadas e a ausência de grandes disparidades entre as capitais em relação à imunização, bem como a apresentação de melhores coberturas em estratos com pior condição econômica, sugerem a efetividade do PNI nas capitais do Nordeste na promoção da equidade em saúde.

Por outro lado, a maioria das crianças estudadas não tinha o esquema básico de vacinação completo, o que nos faz repensar a abordagem das crianças que entram em contato com o serviço em qualquer ocasião e por qualquer motivo (oportunidades perdidas). Além disso, reforça a necessidade de treinamento periódico das equipes que costumam superestimar contraindicações 5,7 .

A distribuição da cobertura vacinal por setores censitários é heterogênea. Os setores onde se encontraram as melhores coberturas vacinais correspondem àqueles cuja população possui renda familiar mais baixa, na maioria das vezes 10 .

$\mathrm{Na}$ presente pesquisa, as coberturas vacinais estimadas mostraram-se mais elevadas em segmentos mais pobres da população, conforme encontrado recentemente em vários países 7,12, mas trabalhos clássicos apontam o contrário 13,14,15. É importante ressaltar que estratos de melhor poder aquisitivo e maior escolaridade obtiveram as menores coberturas em algumas capitais como Recife, Salvador e Fortaleza.

Em estudo semelhante realizado em quatro cidades do Estado de São Paulo, as mães de crianças com melhores condições de vida estariam menos preocupadas com a ocorrência de doenças infecciosas entre seus filhos, dada a extrema redução na incidência dessas doenças nas últimas décadas 14. Exatamente por terem melhores condições, essas mães poderiam avaliar que seus filhos não estariam expostos ao risco de infecção. Por outro lado, tal resultado poderia ser atribuído à ampla cobertura da Estratégia Saúde da Família (ESF) que ampliou a cobertura de ações de prevenção, especialmente em áreas mais carentes das cidades brasileiras. Outra possibilidade que não pode ser descartada é a de que as mães não estivessem dispostas a procurar o documento para mostrá-lo aos entrevistadores, já que as dificuldades para a realização do inquérito foram muito maiores no estrato com melhores condições.

A tendência, reiteradamente verificada, de coberturas baixas nas camadas com melhores condições de vida, representa um desafio a ser enfrentado na garantia do controle das doenças imunopreveníveis. Trata-se provavelmente de um fenômeno recente que merece estudos para identificar características e atitudes das famílias e dos serviços de saúde em diferentes contextos.

O Ministério da Saúde estabelece meta de cobertura vacinal de $90 \%$ para a vacina contra a tuberculose (BCG), 95\% para poliomielite, 95\% para a vacina tetravalente (contra tétano, difteria, coqueluche - DPT e meningite - Hib), 95\% para hepatite B e 95\% para vacina tríplice viral (SCR - contra caxumba, rubéola e sarampo) 14. $\mathrm{Na}$ maioria das capitais, as coberturas vacinais analisadas de forma individualizada encontram- 
se próximas de $85 \%$. No entanto, mesmo a cobertura para cada vacina específica sendo alta, nenhuma delas atingiu esse patamar. Ao comparar esses resultados com os de pesquisa realizada em dois municípios do Estado da Bahia no ano de 1997, foi observada situação semelhante 16 .

Moraes \& Ribeiro 7 encontraram diferenças nas coberturas das vacinas pólio, DTP/Hib e hepatite $\mathrm{B}$, considerando que o esquema básico, para as três vacinas, completa-se aos seis meses de idade, conforme verificado no presente estudo.

Mesmo que a diferença na cobertura seja pequena, esse fato pode sugerir, de alguma maneira, falhas de registro nas salas de vacina já apontadas em comparações realizadas entre dados de inquéritos de cobertura vacinal e dados administrativos, ou ainda a não realização das vacinas nos intervalos corretos 7. Tal diferença remete também a possíveis dificuldades dos serviços e usuários em adequar a aplicação da última dose da vacina contra hepatite $B$ aos seis meses de idade juntamente com as últimas doses da pólio e DTP/tetra. O esquema da vacina contra a hepatite B é diferente, pois a 2a dose deve ser feita com um mês de idade e, havendo um atraso igual ou superior a cinco meses na aplicação da $2 \underline{a}$ dose, o esquema já não será completado aos seis meses juntamente com a pólio e DTP/tetra 17,18.

É importante assinalar que a despeito de os programas de imunização serem desenhados como estratégias de prevenção em massa, devendo alcançar coberturas universais e sendo oferecidos gratuitamente a toda a população, as desigualdades sociais se mantêm. O único aspecto discrepante é representado pelas coberturas mais baixas nas crianças do estrato A. Tal discrepância pode ser entendida como uma característica de comportamento dessas famílias, mais do que como o efeito de restrições socioeconômicas ou outros problemas de acesso às vacinas 19 .

O grau de estruturação do programa de imunização interfere na cobertura vacinal, junto a outros dois condicionantes: a política de saúde e características da população, portanto outra justificativa possível para a insipiência desse dado é o entendimento do senso comum acerca da indicação e da importância das inúmeras vacinas na prevenção de várias doenças 17.

\section{Conclusão}

Os achados da presente investigação trazem importantes informações em relação à cobertura vacinal e às atividades de vacinação para os serviços de saúde. Os resultados do inquérito domiciliar mostraram índices satisfatórios de cobertura por vacina, para a BCG, hepatite B, antipólio e $\mathrm{DTP} / \mathrm{Hib}$ (tetra), mas ainda assim as coberturas foram abaixo do preconizado.

Os dados obtidos no presente estudo de cobertura vacinal demonstram que é baixa a proporção de crianças vacinadas, ao se considerarem as metas preconizadas pelo PNI, na faixa etária de maior risco para as doenças imunopreveníveis.

Em todas as capitais do Nordeste, ao se analisar o conjunto de todas as vacinas, as melhores coberturas pertencem à Teresina, sem diferença significativa entre os estratos, a maior parte atingiu valores superiores a $80 \%$, a exceção foi o estrato A. Nas outras capitais, observam-se coberturas em todos os estratos próximo de $47 \%$, exceto o estrato A e E de Recife e São Luís nos estratos A, C e E.

Ao se analisar o cumprimento do calendário básico de vacinação, verifica-se boa cobertura para BCG, sendo a vacina com maior cobertura em todas as capitais estudadas, com valores superiores a $85 \%$, sem diferenças significativas entre os estratos.

Teresina obteve os melhores indicadores para os percentuais de respostas, para a cobertura da maioria das vacinas, apresentando cobertura melhor do que capitais mais antigas e desenvolvidas. Esse fato pode estar relacionado à implementação de políticas públicas mais eficientes.

Os resultados sugerem que inquéritos de cobertura vacinal deveriam ser realizados frequentemente. Além disso, é importante treinar os funcionários das salas de vacinação para que preencham adequadamente os dados de vacinação, intensificar a divulgação do calendário oficial de imunização aos profissionais de saúde e facilitar o acesso da população aos serviços de saúde. A avaliação da cobertura vacinal contribui para obtenção de respostas relacionadas à efetividade da ação para detectar se a população infantil encontra-se imunizada, além da identificação de pontos frágeis das atividades de vacinação.

Os programas de imunização necessitam de uma detalhada revisão para identificar os fatores que geram a baixa cobertura e a alta taxa de abandono, além da identificação de medidas que possam sanar esses problemas. Qualquer programa de saúde somente se mantém com desempenho adequado se for continuadamente monitorado e aperfeiçoado. 


\section{Resumen}

La cobertura de las vacunas en los denominados "países en desarrollo" todavía está por debajo de lo esperado. Se trata de un importante indicador de salud de la población y de la calidad de la atención dispensada por los servicios de salud. El presente estudio describe los resultados de una encuesta domiciliaria para estimar la cobertura de vacunación en el esquema básico de salud durante el primer año de vida, concretamente en la cohorte nacida en 2005, en las capitales del nordeste brasileño. La metodología usada es la preconizada por la Organización Pan-Americana de la Salud para la realización de encuestas de cobertura de vacunación. Los datos obtenidos en el presente estudio de cobertura de vacunación demuestran que es baja la proporción de niños vacunados, al ser consideradas las metas preconizadas por el Programa Nacional de Inmunización, en la franja de edad de mayor riesgo para las enfermedades inmunizables. En lo que se refiere a los estratos en las capitales del Nordeste, encontramos las peores coberturas en los dos extremos de los estratos socioeconómicos. La evaluación de la cobertura de vacunación contribuye a detectar si la población infantil se encuentra inmunizada, además de permitir la identificación de puntos frágiles en las actividades de vacunación.

Cobertura de Vacunación; Inmunización; Lactente; Encuestas

\section{Colaboradores}

L. L. C. Queiroz participou da concepção do artigo, revisão bibliográfica, analise dos dados e redação do texto. S. G. Monteiro foi responsável pelo tratamento estatístico, análise dos dados e aprovação da versão final. E. G. Mochel contribuiu com o delineamento do estudo, a análise dos dados, revisão crítica e aprovação do manuscrito final. M. A. S. M. Veras colaborou no delineamento do estudo, revisão crítica e aprovação do manuscrito final. F. G. M. Sousa e M. B. C. Chein contribuíram na revisão crítica e aprovação do manuscrito final. M. L. M. Bezerra colaborou na coleta de dados, revisão da bibliografia, análise estatística e aprovação da versão final.

\section{Agradecimentos}

À Fundação de Amparo à Pesquisa do Maranhão (FAPEMA) pelo financiamento.

\section{Outros membros do Grupo Inquérito Cobertura Vacinal 2007}

D. C. C. Afonso, M. B. C. Antunes, R. B. Barata, H. A. Barbosa, P. C. Castro, M. C. J. W. Cortes, B. Flannery, E. B. França, S. G. N. Gama, I. A. Guibu, M. C. Leal, E. J. A. Luna, M. L. R. Mello, S. S. Mengue, J. C. Moraes, M. J. Penon-Rujula, S. M. Pereira, M. C. S. A. Ribeiro, R. M. C. Santos e O. Simões.

\section{Referências}

1. Silveira ASA, Silva BMF, Peres EC, Meneghin P. Controle de vacinação de crianças matriculadas em escolas municipais da cidade de São Paulo. Rev Esc Enferm USP 2007; 41:299-305.

2. Roncalli AG, Lima KC. Impacto do Programa de Saúde da Família sobre indicadores de saúde da criança em municípios de grande porte da região Nordeste do Brasil. Ciênc Saúde Coletiva 2006; 11:713-24.
3. Moraes JC, Ribeiro MCSA, Simões O, Castro PC, Barata RB. Qual é a cobertura vacinal real? Epidemiol Serv Saúde 2003; 12:147-53.

4. Araújo TME, Sá LC, Silva AAS, Costa JP. Cobertura vacinal e fatores relacionados à vacinação dos adolescentes residentes na área norte de Teresina/ PI. Rev Eletrônica Enferm 2010; 12:502-10. 
5. Travassos C, Martins M. Uma revisão sobre os conceitos de acesso e utilização de serviços de saúde. Cad Saúde Pública 2004; 20 Suppl 2:S190-8.

6. Atkinson WL, Pickering LK, Schwartz B, Weniger BG, Iskander JK, Watson JC, et al. General recommendations on immunization. Recommendations of the Advisory Committee on Immunization Practices (ACIP) and the American Academy of Family Physicians (AAFP). MMWR Recomm Rep 2002; 51:1-35.

7. Moraes JC, Ribeiro MCSA. Desigualdades sociais e cobertura vacinal: uso de inquéritos domiciliares. Rev Bras Epidemiol 2008; 11 Suppl 1:113-24.

8. Temporão JG. O Programa Nacional de Imunizações (PNI): origens e desenvolvimento. Hist Ciênc Saúde-Manguinhos 2003; 10 Suppl 2:601-17.

9. Barata RC. Desigualdades sociais em saúde. In: Campos GWS, Minayo MCS, organizadores. Tratado de saúde coletiva. São Paulo: Editora Hucitec/ Rio de Janeiro: Editora Fiocruz; 2006. p. 457-86.

10. Smith A, Yarwood J, Salisbury DM. Tracking mothers' attitudes to MMR inmunization 1996-2006. Vaccine 2007; 25:3996-4002.

11. Ministério da Saúde. Estatuto da criança e do adolescente. 3a Ed. Brasília: Ministério da Saúde; 2006.

12. Ali M, Thiem VD, Park JK, Ochiai RL, Canh do G, Danovaro-Holliday MC, et al. Geographic analysis of vaccine uptake in a cluster-randomized controlled trial in Hue, Vietnam. Health Place 2007; 13:577-87.

13. Delamonica E, Minujin A, Gulaid J. Monitoring equity in immunization coverage. Bull World Health Organ 2005; 83:384-91.
14. Moraes JC, Barata RB, Ribeiro MCSA, Castro PC. Cobertura vacinal no primeiro ano de vida em quatro cidades do Estado de São Paulo, Brasil. Rev Panam Salud Pública 2000; 8:332-41.

15. Ortega MP, Astasio AP, Albaladejo V, Aráosla MP, Villanueva OR, Ramón DJPJ. Mantenimiento de la cadena del frío para las vacunas: una revisión sistemática. Gac Sanit 2007; 21:343-8.

16. Porto LA. Cobertura vacinal nos municípios de Iguaí e Caldeirão Grande, Bahia, em 1997. Inf Epidemiol SUS 1998; 7:7-24.

17. Oliveira MAC, Takahashi RF. Questões práticas relacionadas à aplicação de vacinas. In: Farhat CK, Carvalho ES, Weckx LY, Carvalho LHF, Succi RCM, organizadores. Imunizações: fundamentos e prática. 4a Ed. São Paulo: Editora Atheneu; 2000. p. 137-48.

18. França ISX, Simplício DN, Alves FP, Brito VRS. Cobertura vacinal e mortalidade infantil em Campina Grande, PB, Brasil. Rev Bras Enferm 2009; 62:258-64.

19. Facchini LA, Piccini RX, Tomasi E, Thumé E, Silveira DS, Siqueira FV, et al. Desempenho do PSF no Sul e no Nordeste do Brasil: avaliação institucional e epidemiológica da atenção básica à saúde. Ciênc Saúde Coletiva 2006; 11:669-81.

Recebido em 04/Fev/2012

Versão final reapresentada em 11/Out/2012

Aprovado em 17/Out/2012 